\title{
DETERMINATION OF IN-PLANE SHEAR PROPERTIES OF LAMINATE WITH V-NOTCH RAIL SHEAR TEST AND DIGITAL IMAGE CORRELATION
}

\author{
Maciej Karny \\ Composites Testing Lab, Composites Technology Center, Institute of Aviation, \\ al. Krakowska 110/114, 02-256 Warsaw, Poland \\ maciej.karny@ilot.edu.pl
}

\begin{abstract}
This article presents the results of the application of Digital Image Correlation (DIC) to measurements of in-plane shear modulus and strength of three different carbon fiber reinforced laminates. Three different approaches to shear strain calculations via DIC are evaluated and compared with standard strain gage measurements. Calculation of shear strain based on averaging DIC strain values of strain gages area in most cases yielded results closest to strain gages, while measurements based on single point strain measuring differed the most from strain gages. These results are attributed to shear strain distribution in the center area of the specimen. Thermoplastic matrix fabric reinforced composite had the lowest shear strength at $5 \%$ of shear strain, but the highest ultimate shear strength and strain at failure. Of thermosetting materials, laminate reinforced with unidirectional carbon fiber had shear modulus about $10 \%$ lower, than fabric reinforced laminate, but higher ultimate strength and strain at failure. This behavior is attributed to the presence of weaves in fabric reinforcing the laminate, causing shear stiffening of the material, but lowering its ability to deform under shear loading.
\end{abstract}

Keywords: Digital Image Correlation, in-plane shear, thermoplastic laminates, v-notch rail shear

\section{INTRODUCTION}

Modern aircraft design, as well as the production process, rely heavily on numeric simulations, for instance, with the use of finite element analysis (FEA). Nonetheless, these simulations have to be verified and validated for being deemed as reliable $[1,2]$. The obvious method of validation is performing mechanical tests of modelled components. Traditionally, strain measurements in these tests are carried out with strain gages, extensometers or LVDT sensors. While accurate, these sensors provide strain data only from small areas (strain gages) or linear displacement (extensometers, LVDT), but do not provide 
information about strain fields and possible stress concentrations. Among others, this is the reason for developing full-field strain measurement technics, such as photoelasticimetry, speckle interferometry or digital image correlation (DIC), with the last being arguably most popular in recent years $[1,3,4]$. The basis of DIC is the processing of images of specimen or component, captured during the test. To achieve this, the analyzed surface has to be covered with random black and white speckle pattern, which is later recognized by the software and used to calculate required strains, displacements, etc. By choosing measurement parameters, such as the number of cameras, picture resolution and camera lenses, it is possible to perform measurements on relatively large and complicated surfaces and objects $[6,7]$. Contrary to strain gages, digital image correlation can show strain distribution across the whole measured surface. DIC has been successfully used in many applications, e.g. validating FEA models of wing parts [2], assessing material performance under biaxial loading [8] or measuring composite material properties (Young modulus, Poisson ratio, shear properties), among others [3, 5, 6, 9, 10]. Among these, shear measurements seem to be of high value - shearing of material is complex process with multi-axial, often nonuniform state of strain. Testing shear properties of composite materials is of very high importance, as shearing of these materials is not as straightforward, as in case of isotropic metallic materials. The main goal of shearing tests is obtaining a pure shear state in the material, which can be achieved with various test methods. The two more common shearing tests for fiber-reinforced composited are Iosipescu shear test and the V-notch rail shear test (ASTM D5379 and D7078, respectively) [11]. However, the Iosipescu test tends to be difficult to perform and produces errors in shear modulus measurements, due to small specimen size and sensitivity to fibers' orientation [12]. Therefore, the $\mathrm{V}$-notch rail shear test is preferred in the testing of many fiber-reinforced laminates, especially textile reinforced or high strength ones $[11,13,14]$. Shearing properties of fiber-reinforced composite tend to be governed by polymer matrix and fiber-matrix interface properties, rather than by the strength of fibers alone $[15,16]$. Also, the type of fiber reinforcement (textile or unidirectional), lay-up (especially the amount $\pm 45^{\circ}$ oriented fibers) and type of the matrix (thermosetting or thermoplastic) have a very large influence on overall shear performance of the material. Thermoplastic matrix composites, due to their higher plasticity and better fatigue properties are exhibiting much-improved shear properties, when compared to thermosetting matrix laminates [17].

This article presents the results of shear tests of 3 different carbon fiber reinforced composites, performed according to the $\mathrm{V}$-notch rail shear test method with the use of digital image correlation. Shear properties of these materials are compared and the validity of DIC measurement for shear modulus measurement is assessed and discussed.

\section{METHODOLOGY OF TESTS}

Three carbon fiber reinforced composites were tested according to D7078/D7078M-12 Standard test method for shear properties of composite materials by $V$-notched rail shear method [18]; figure 1 presents schematic of this test. Tested materials were: thermoplastic (PEEK) matrix - fabric carbon fiber laminate, epoxy matrix - fabric carbon fiber laminate and produced in AFP technology epoxy matrix - unidirectional carbon fiber laminate. All of the tested laminates had $[0 / 90]_{4 S}$ lay-up. Tests were performed in 3 different fibers orientations relatively to load direction, with the first layer of fibers being oriented perpendicular (fig. 2A)), parallel (fig. 2B)) or $45^{\circ}$ turned to load axis (fig. 2C)). 


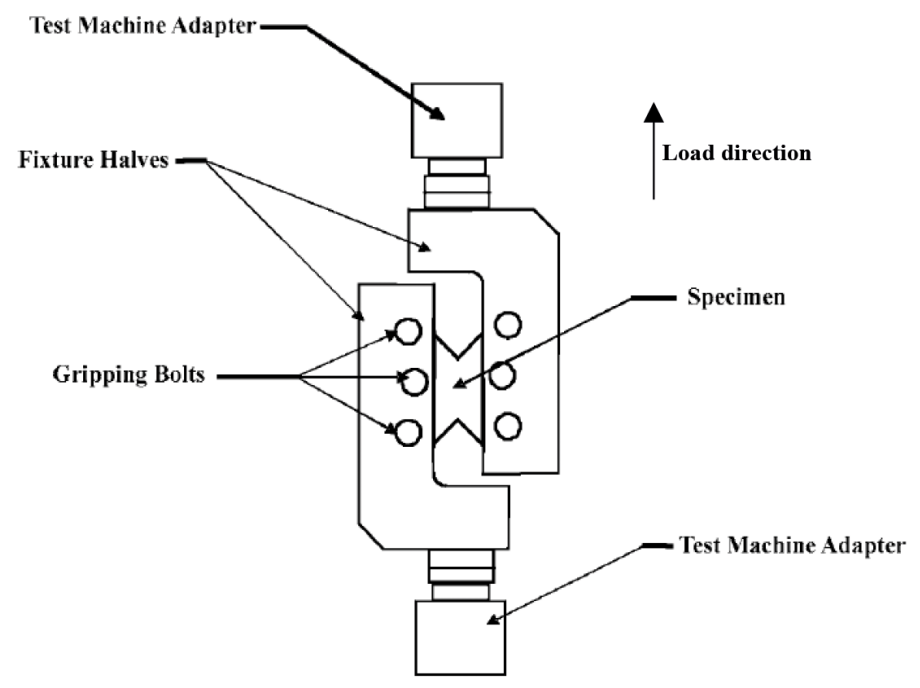

Figure 1. Shear test schematic. Source: ASTM D7078/D7078M-12 [18]

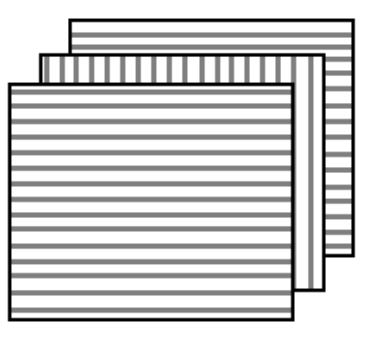

A)

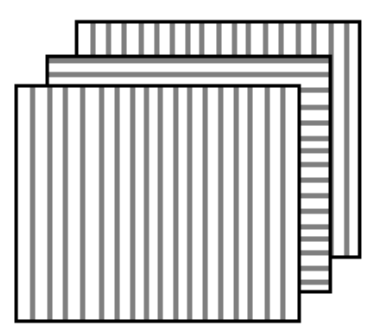

B)

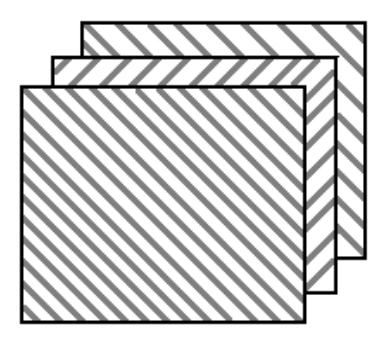

C)

Figure 2. Tested fiber orientations: A - orientation $1\left(\mathrm{G}_{12}\right), B$ - orientation $2\left(\mathrm{G}_{21}\right), \mathrm{C}$ - orientation $3\left(\mathrm{E}_{11}\right)$. Source: author's work.

Strain measurements were performed in two ways - with strain gages and digital image correlation. Strain gages were of standard, two grid rosette type with $0.125 ”(3.175 \mathrm{~mm})$ gage length. According to standard, gages were placed in $\pm 45^{\circ}$ orientation relative to the loading direction. DIC images were captured in 1 - second intervals with a Nikon D300 camera with telephoto lens and resolution 4496 x 3000 pixels (13.5 Mpx). Digital image correlation was then performed with dedicated software, with a facet size of 25 pixels and point distance 15 pixels. Strain values for modulus calculation were obtained in three ways: by taking single point strain from the middle of the specimen, by calculating average $\mathrm{X}$ - and $\mathrm{Y}$ - direction strains in strain gage area $\left(\varepsilon_{\mathrm{x}} \& \varepsilon_{\mathrm{y}}\right)$ and adding them (as it is done with strain gages' strains) and by calculating average shear strain in strain gage area (fig. 3). 


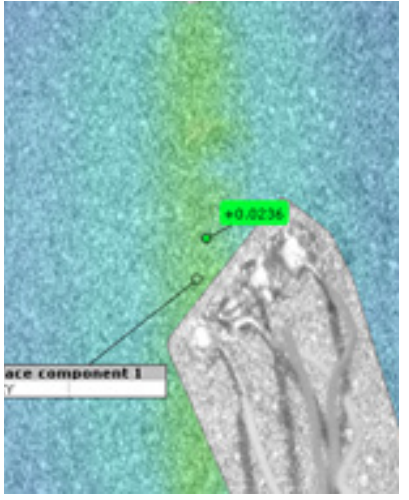

A)

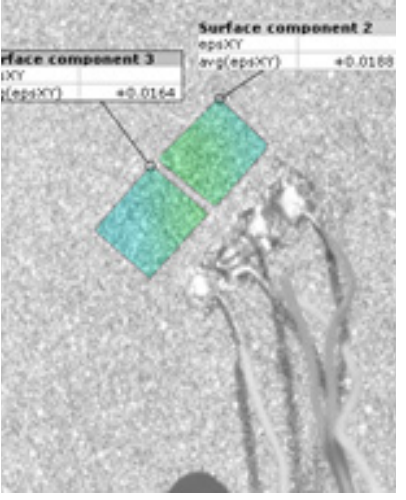

B)

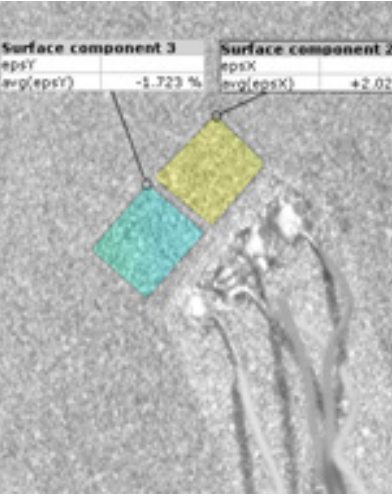

C)

Figure 3. Strain calculation methods: A - single point strain (“SP-DIC”), B - strain gage area average shear strain (“AVG-DIC"), C - the sum of strain gage area average X and Y strains ("XY-DIC”).

\section{TEST RESULTS}

The objective of the work was to compare shear strain (especially in shear modulus strain range, $2000 \div 6000 \mu \varepsilon$ ) measurement between strain gages and digital image correlation to establish whether DIC can be a reliable alternative to traditional shear strain measurements. Comparison of average shear modulus values for all of the tested materials and shear measurement method is presented in table 1 . $\mathrm{TP}-\mathrm{FAB}=$ thermoplastic matrix + fabric fiber reinforcement, TS-FAB $=$ thermosetting matrix + fabric fiber reinforcement, TS-UD = thermosetting matrix + unidirectional fiber reinforcement.

Table 1. Average shear moduli for all of the tested series. Bold are the values closest to strain gage (SG) results. In parentheses are the differences between strain gage measured modulus and respective measurements.

\begin{tabular}{|c|c|c|c|c|c|}
\hline Material & Orientation & \multicolumn{4}{|c|}{ Shear Modulus, MPa } \\
\hline \multicolumn{3}{|c|}{ SG } & SP-DIC & XY-DIC & AVG-DIC \\
\hline \multirow{3}{*}{ TP-FAB } & 01 & 4828 & $\begin{array}{c}5123 \\
(+6.11 \%)\end{array}$ & $\begin{array}{c}4966 \\
(+2.86 \%)\end{array}$ & $\begin{array}{c}4700 \\
(-2.65 \%)\end{array}$ \\
\hline & 02 & 4858 & $\begin{array}{c}4327 \\
(-10.93 \%)\end{array}$ & $\begin{array}{c}4334 \\
(-10.79 \%)\end{array}$ & $\begin{array}{c}4310 \\
(-11.29 \%)\end{array}$ \\
\hline & 03 & 26430 & $\begin{array}{c}24533 \\
(-7.18 \%)\end{array}$ & $\begin{array}{c}24601 \\
(-6.92 \%)\end{array}$ & $\begin{array}{c}24665 \\
(-6.68 \%)\end{array}$ \\
\hline \multirow{3}{*}{ TS-FAB } & 01 & 4758 & $\begin{array}{c}4676 \\
(-1.72 \%)\end{array}$ & $\begin{array}{c}4619 \\
(-2.92 \%)\end{array}$ & $\begin{array}{c}4468 \\
(-6.09 \%)\end{array}$ \\
\hline & 02 & 4810 & $\begin{array}{c}4351 \\
(-9.54 \%)\end{array}$ & $\begin{array}{c}4482 \\
(-6.81 \%)\end{array}$ & $\begin{array}{c}4638 \\
(-3.57 \%)\end{array}$ \\
\hline & 03 & 28171 & $\begin{array}{c}24791 \\
(-12.31 \%)\end{array}$ & $\begin{array}{c}26169 \\
(-7.44 \%)\end{array}$ & $\begin{array}{c}26472 \\
(-6.36 \%)\end{array}$ \\
\hline
\end{tabular}




\begin{tabular}{|c|c|c|c|c|c|}
\hline Material & Orientation & \multicolumn{4}{|c|}{ Shear Modulus, $\mathrm{MPa}$} \\
\hline \multirow{3}{*}{ TS-UD } & 01 & 4439 & $\begin{array}{c}4315 \\
(-2.80 \%)\end{array}$ & $\begin{array}{c}4570 \\
(+2.94 \%)\end{array}$ & $\begin{array}{c}4533 \\
(+2.11 \%)\end{array}$ \\
\hline & 02 & 4403 & $\begin{array}{c}4469 \\
(+1.50 \%)\end{array}$ & $\begin{array}{c}4468 \\
(+1.48 \%)\end{array}$ & $\begin{array}{c}4453 \\
(+1.14 \%)\end{array}$ \\
\hline & 03 & 30058 & $\begin{array}{c}28185 \\
(-6.23 \%)\end{array}$ & $\begin{array}{c}28656 \\
(-4.66 \%)\end{array}$ & $\begin{array}{c}29138 \\
(-3.06 \%)\end{array}$ \\
\hline
\end{tabular}

These results show that in most of the test series, shear moduli calculated with average strain gage area shear strain measured by DIC is the closest to the values of moduli calculated with strain gages measurements, with the average difference between results of 4.77\%. Except for TS-UD-01 and TP-FAB-02 series, the XY-DIC method was second closest to strain gage values (average difference $5.20 \%$ ), were single - point strain DIC method in most of the series differed the most from strain gages (average difference 6.48\%). The difference between SP-DIC values and strain gage values can be easily attributed to the character of the measurement: in SP-DIC strain value is taken from a single point in the middle of the coupon, wherein strain gage measurement, strain value is a sum of longitudinal strains from two strain gages, oriented at $\pm 45^{\circ}$ relative to load axis. The actual strain from strain gage is an average value of strain under the gage, which is approximately $10 \mathrm{~mm}^{2}$ in this case. Therefore, strain gage may cover not only the maximum shear strain area but also an adjacent area of a lower strain, resulting in observed difference. This is shown in figure 4.
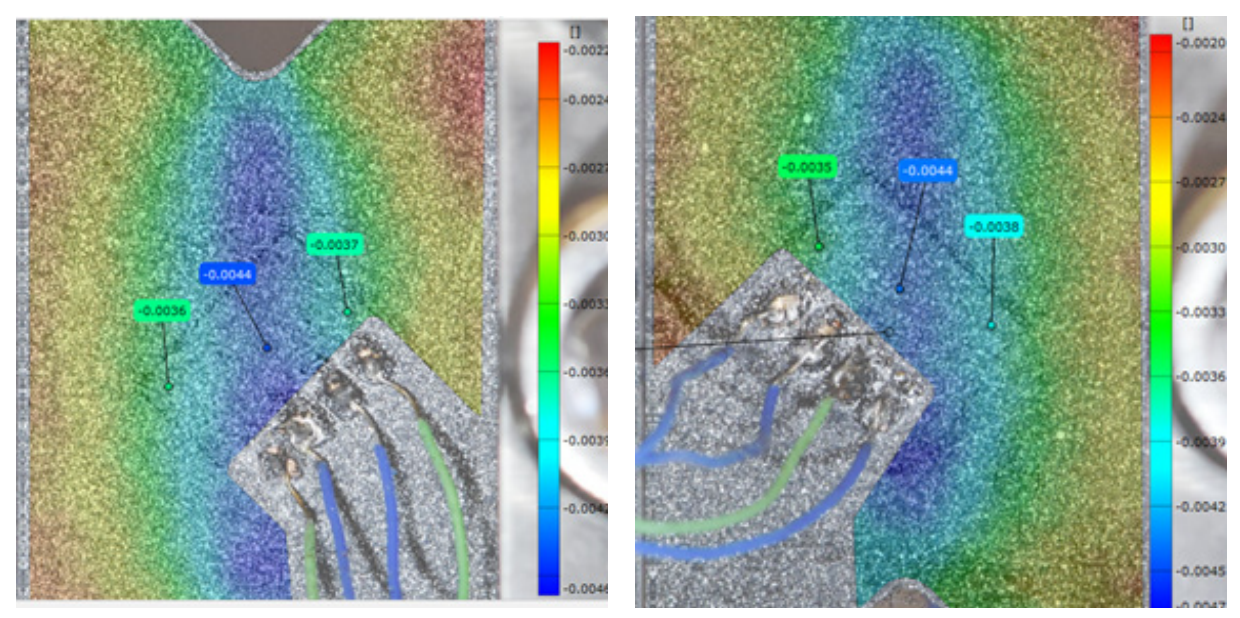

Figure 4. Shear strain distribution in strain gage area for thermosetting matrix, unidirectional fiber reinforced laminate. Left: orientation 1, right: orientation 2.

The difference in shear strain across strain gage area for thermosetting matrix-unidirectional fiber-reinforced laminate (3.175-mm gage length) can be as high as $0.09 \%$ (900 microstrains), which is significant, considering strain range for modulus determination between $0.2 \%$ and $0.6 \%$ of shear strain. Strain distribution also can be attributed to observed differences between two other measuring methods (XY-DIC and AVG-DIC) and strain gage results. Strain gage yields strain of its working 
element (measuring grid), which is the strain of the metallic wire forming the grid. The basis of this measurement is an assumption, that wire is deforming uniformly across its whole length, which means that it is insensitive to small strain variations in the material under the strain gage. DIC measurement, however, can capture these variations and differences in strain distribution, which later affect the result of averaging of the strain in the measured area. These effects probably could be reduced by using strain gages with smaller gage length, however, smaller strain gages are much more difficult to align and bond properly. Also, in case of fabric reinforced composites, small the strain gages would be more sensitive to the presence of weaves, resulting in larger error. Another thing, that can be noted in results in table 1 is larger differences between strain gage and DIC results for orientation 2 coupons than for orientation 1 ones in fabric reinforced composites. For thermoplastic composite, the average difference between SG and DIC measurements was $3.87 \%$ for orientation 1 and $11.0 \%$ for orientation 2 coupons. For thermosetting laminate, these differences were $3.58 \%$ and $6.64 \%$, respectively. Whether this effect comes from measuring technique or material itself will be evaluated in future tests.

When comes to comparison between tested materials, there are also visible differences. Although shear modulus is comparable for both of textile reinforced materials (TP-FAB and TS-FAB), it is about $10 \%$ lower for unidirectional material. This difference is attributed to the presence of the weaves in fabric type reinforcements, which hinders fibers movement and decreases shear deformation, hence increase shear modulus. Comparison of stress- DIC strain curves of tested materials are presented in figure 5. Orientations $1 \& 2$ are chosen for comparison, as they are equivalent to each other, i.e. $\gamma_{12}=\gamma_{21}$. Only DIC measurements allowed to measure the ultimate shear strain of tested composites, as strain gages data becomes unreliable at shear strains higher than $10 \%$ and strain gages completely fail at shear strains below 20\%. DIC, however, does not have such strain limit.
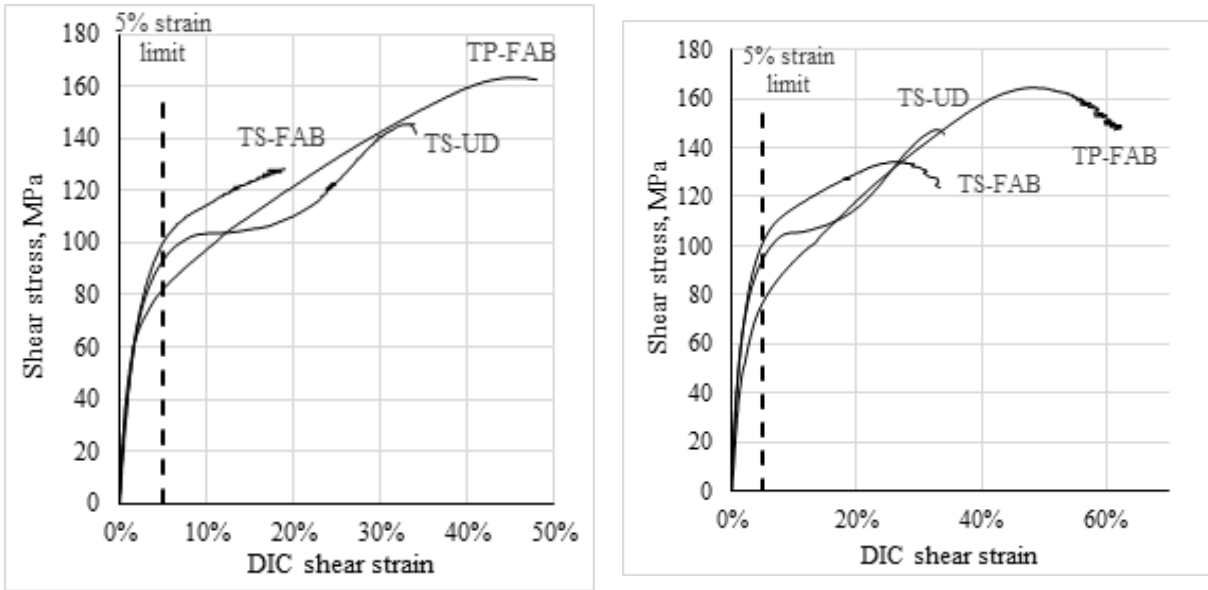

Figure 5. Representative stress-DIC strain curves for tested materials. Left: orientataion $1\left(\gamma_{12}\right)$, right: orientation $2\left(\gamma_{21}\right)$.

Although having similar shear modulus values, tested materials exhibit significantly different behavior at larger shear strain values. Thermoplastic matrix composite has the lowest shear strength at $5 \%$ strain level (given as ultimate strain value in the standard [18]), also shown in table 2, but shows the highest shear strength and strain at failure of tested materials. Thermoplastic matrix composite reaches 
strength comparable to $5 \%$ strain level strength of thermosetting material at $12-13 \%$ shear strain, which is over twice the ultimate strain value given by the D7078 standard. If shear strength was to be the main design value, calculating values according to the D7078 standard would give underestimated results about the true strength of the material. However, reliable measuring shear strains of this magnitude is troublesome, mostly due to strain gages limitations and significant rotation of the fibers at this levels of strain (as mentioned in point 6.1.3 of ASTM D3518/D3518M-13 Standard test method for in-plane shear response of polymer matrix composite materials by tensile test of a $\pm 45^{\circ}$ laminate, [19]). Nonetheless, this discrepancy between thermoplastic and thermosetting composites shear behavior may need to be addressed in future revisions of the D7078 standard. Between thermosetting-matrix composites, unidirectional fiber-reinforced composite shows higher ultimate shear stress and strain, despite having lower shear modulus, than other materials. There is also the clear difference in material behavior between unidirectional and fabric reinforcement. After 5\% of shear strain, fabric-reinforced material is gradually and steadily increasing stress up to the rupture, while UD material has a plateau region, where stress increases slowly, up to $20 \%$ of shear strain, where stress starts to rise rapidly up to failure at about $35 \%$ of shear strain. Gradual stress increase in fabric-reinforced material can be explained by the presence of the weaves in the reinforcement, as mentioned earlier. In case of UD material, lack of weaves stopping fibers movement causes easier deformation of the material, hence causing the stress-strains plateau. At about $20 \%$ of shear strain however, fibers movement space is saturated, and the material starts to strengthen up to failure.

Table 2. Values of 5\% strain shear stress and ultimate stress and strain of tested materials.

\begin{tabular}{|l|c|c|c|}
\hline Test series & $\begin{array}{c}\text { Average stress at 5\% } \\
\text { of shear strain, MPa }\end{array}$ & $\begin{array}{c}\text { Average ultimate shear } \\
\text { strength, MPa }\end{array}$ & $\begin{array}{c}\text { Average shear strain } \\
\text { at ultimate strength }\end{array}$ \\
\hline TP-FAB-1 & 82.42 & 161.3 & $45.75 \%$ \\
\hline TP-FAB-2 & 83.03 & 165.0 & $48.60 \%$ \\
\hline TS-FAB-1 & 105.20 & 130.1 & $22.88 \%$ \\
\hline TS-FAB-2 & 105.68 & 135.0 & $26.19 \%$ \\
\hline TS-UD-1 & 100.95 & 147.5 & $33.24 \%$ \\
\hline TS-UD-2 & 97.26 & 145.5 & $32.83 \%$ \\
\hline
\end{tabular}

\section{CONCLUSIONS}

Results of the performed tests allow to form the following conclusions:

1. In most of the tested series, the DIC method basing on the averaging shear strain of strain gage area produced values of shear modulus closest to these obtained with strain gage measurements. The average difference in modulus value between these two methods was $4.77 \%$.

2. DIC measurements allowed to observe strain distribution in strain gage area. For 3.175-mm gage length the strain gage, differences in shear strain between the center and the edge of gage can be as high as 900 microstrains (0.9\%). This suggests that using smaller strain gages in shear strain measurement may be beneficial in some cases. Also, this is the reason, why single point strain measurement (SP-DIC) showed the largest difference, compared to strain gage measurement: $6.48 \%$. 
3. DIC is the only method, that allows reliably measure very high shear strains, where strain gages fail. Strains at ultimate shear strength can be as high as $50 \%$ for thermoplastic composites, which is far beyond standard strain gage measurement range.

4. Thermoplastic matrix fabric reinforced composite has $22 \%$ lower shear strength at $5 \%$ shear strain, than thermosetting matrix fabric reinforced composite. However, thermoplastic composite has 23\% higher ultimate strength and over $92 \%$ higher strain at failure- than thermosetting matrix fabric laminate. This proves higher strengthening and damage accumulation capability of thermoplastic laminate. Also, these hints possible need of adjustment of existing standards to acknowledge thermoplastic composites' different behavior.

5. Unidirectional reinforcement composite showed 7.6\% lower shear modulus and 6\% lower shear strength at 5\% shear strain, but $10 \%$ higher ultimate shear strength and 35\% higher strain at failure, than fabric reinforced laminate of the same type of matrix.

\section{REFERENCES}

[1] Kowalczyk P., "On applications of optical full-field strain measurements in validation and examination procedures", Transactions of the Institute of Aviation, No. 4(245), 2016, 46-51, DOI: $10.5604 / 05096669.1226354$

[2] Bajurko P., Dobrzański P., 2018, "Experimental verification of numerical calculations with the use of digital image correlation", Transactions of the Institute of Aviation, No. 2(251), 7-21

[3] F. Lagattu. J. Brillaud, M.-C. Lafarie-Frenot, "High strain gradient measurements by using digital image correlation technique", Materials Characterization, 53, 2004, 17-28, DOI: 10.1016/j. matchar.2004.07.009

[4] Malesa M. et al., "Hybrid GI-DIC measurement procedure for hierarchical assessment of strain fields”, Measurement, Vol. 134, 2019, 83-88, DOI: 10.1016/j.measurement.2018.10.078

[5] Kowalczyk P., 2019, "Identification of mechanical parameters of composites in tensile tests using mixed numerical-experimental method”, Measurement, Vol. 135, 2019, 131-137, DOI: 10.1016/j.measurement.2018.11.027

[6] He Y., Makeev A., Shonkwiler B., "Characterization of nonlinear shear properties for composite materials using digital image correlation and finite element analysis”, Composites Science and Technology, 73, 2012, 64-71 DOI: 10.1016/j.compscitech.2012.09.010

[7] Kalariya Y. et al., "Applications of digital image correlation technique in composite research", (conference paper, $9^{\text {th }}$ International Symposium on Advanced Science and Technology in Experimental Mechanics, New Delhi, India, 1-6 November 2014), DOI: 10.13140/2.1.5074.1442

[8] Perie J. N. et al., "Digital Image Correlation and biaxial test on composite material for anisotropic damage law identification”, Int. Journal of Solids and Structures, 46, 2009, 2388-2396, DOI: 10.1016/j.ijsolstr.2009.01.025

[9] Acciaioli A. et al., "Experimentally achievable accuracy using a digital image correlation technique in measuring small-magnitude $(<0.1 \%)$ homogeneous strain fields", Materials, 11, 2018, 751, DOI: $10.3390 / \mathrm{ma1} 1050751$

[10] Hufenbach W. et al., "Analysing and modelling the 3D shear damage behavior of hybrid yarn textile-reinforced thermoplastic composites", Composite Structures, 94, 2011, 121-131, DOI: 10.1016/j.compstruct.2011.07.010 
[11] Olsson R., "A survey of test methods for multiaxial and out-of-plane strength of composite laminates", Composites Science and Technology, 71, 2011, 773-783, DOI: 10.1016/j.compscitech.2011.01.022

[12] Cognard J.Y, Sohier L., Davies P., "A modified Arcan test to analyze the behavior of composites and their assemblies under out-of-plane loadings", Composites: Part A, 42, 2011, 111-121, DOI: 10.1016/j.compositesa.2010.10.012

[13] Gude M., et al., "Modified V-notched rail shear test fixture for shear characterization of textile-reinforced composite materials", Polymer Testing, 43, 2015, 147-153, DOI: 10.1016/j.polymertesting.2015.03.007

[14] Adams D., "Shear testing of high-shear strength composite laminates", Composites World, vol. 4, No.7, 2018, 10-11

[15] Almeida J.H.S. et al., "Effect of fiber orientation on the shear behavior of glass fiber/epoxy composites”, Materials and Design, 65, 2015, 789-795, DOI: 10.1016/j.matdes.2014.10.003

[16] Totry E. et al., "Effect of fiber, matrix and interface properties on the in-plane shear deformation of carbon-fiber reinforced composites", Composites Science and Technology, 70, 2010, 970-980, DOI: $10.1016 /$ j.compscitech.2010.02.014

[17] Stanley W. F., Mallon P.J., "Intraply shear characterization of a fibre reinforced thermoplastic composite", Composites: Part A, 37, 2006, 939-948, DOI: 10.1016/j.compositesa.2005.03.017

[18] Standard test method for shear properties of composite materials by V-notched rail shear method, ASTM D7078/D7078M-12 (West Conshohocken, PA: ASTM International, approved July 15, 2012). DOI: 10.1520/D7078_D7078M-12

[19] Standard test method for in-plane shear response of polymer matrix composite materials by tensile test of a $\pm 45^{\circ}$ laminate, ASTM D3518/D3518M-13 (West Conshohocken, PA: ASTM International, approved August 1, 2013). DOI: 10.1520/D3518_D3518M-13 